\title{
Transport phenomena and fouling in vacuum enhanced direct contact membrane distillation: Experimental and modelling
}

\author{
Gayathri Naidu $^{\mathrm{a}}$, Wang Geun Shim ${ }^{\mathrm{a}, \mathrm{b}}$, Sanghyun Jeong ${ }^{\mathrm{a}, \mathrm{c}}$, YoungKwon Choi ${ }^{\mathrm{a}}$, Noreddine Ghaffour ${ }^{\mathrm{c}}$ \\ Saravanamuthu Vigneswaran ${ }^{\text {a, * }}$
}

\footnotetext{
${ }^{\text {a }}$ Faculty of Engineering, University of Technology Sydney (UTS), P.O. Box 123, Broadway, NSW 2007 Australia,

${ }^{\mathrm{b}}$ Department of Polymer Science and Engineering, Sunchon National University, 255 Jungang-ro, Sucheon-si, Jellanam-do 57922, Republic of Korea,
}

${ }^{\mathrm{c}}$ King Abdullah University of Science and Technology (KAUST), Water Desalination and Reuse Center (WDRC), Biological and Environmental Science \& Engineering (BESE), Thuwal 23955-6900, Saudi Arabia

*Corresponding author: Tel +61-2-9514-2641; Fax +61-2-9514-2633; Email: Saravanamuth.Vigneswaran@uts.edu.au

\begin{abstract}
The application of vacuum to direct contact membrane distillation (vacuum enhanced direct contact membrane distillation, V-DCMD) removed condensable gasses and reduced partial pressure in the membrane pores, achieving 37.6\% higher flux than DCMD at the same feed temperature. Transfer mechanism and temperature distribution profile in V-DCMD were studied. The empirical flux decline (EFD) model represented fouling profiles of V-DCMD. In a continuous V-DCMD operation with moderate temperature $\left(55^{\circ} \mathrm{C}\right)$ and permeate pressure $(300 \mathrm{mbar})$ for treating wastewater ROC, a flux of 16.0 $\pm 0.3 \mathrm{~L} / \mathrm{m}^{2} \mathrm{~h}$ and high quality distillate were achieved with water flushing, showing the suitability of V-DCMD for ROC treatment.
\end{abstract}


Keywords: fouling; reverse osmosis concentrate; transfer mechanism; vacuum enhanced direct contact membrane distillation

\begin{tabular}{|c|c|c|c|}
\hline \multicolumn{4}{|c|}{ Nomenclature } \\
\hline $\mathrm{J}$ & Permeate flux $\left(\mathrm{kg} / \mathrm{m}^{2} \cdot \mathrm{h}\right)$ & $\mathrm{r}$ & Membrane pore diameter $(\mathrm{m})$ \\
\hline $\mathrm{C}$ & Mass transfer coefficient & $\eta$ & Water vapor viscosity $(\mathrm{kg} / \mathrm{m} / \mathrm{s})$ \\
\hline $\mathrm{P}$ & Vapor pressure $(\mathrm{Pa})$ & $\varepsilon$ & Membrane porosity \\
\hline $\mathrm{T}$ & Temperature $\left({ }^{\circ} \mathrm{C}\right)$ & $\delta$ & Membrane thickness (m) \\
\hline $\mathrm{D}$ & Diffusion coefficient $\left(\mathrm{m}^{2} / \mathrm{s}\right)$ & $\tau$ & Membrane pore tortuosity \\
\hline $\mathrm{D}_{\mathrm{WA}}$ & Molecular diffusivity coefficient $\left(\mathrm{m}^{2} / \mathrm{s}\right)$ & $k_{0}$ & Flux decline potential \\
\hline M & Molecular mass of water $(\mathrm{kg} / \mathrm{kmol})$ & $k_{1}$ & Rate constant \\
\hline $\mathrm{R}$ & Universal gas constant $(\mathrm{kJ} / \mathrm{kmol} / \mathrm{K})$ & $\mathrm{d}$ & Flux decline kinetic constant \\
\hline $\mathrm{P}_{\text {total }}$ & Total pressure inside the pore $(\mathrm{Pa})$ & $\gamma_{\mathrm{w}}$ & Activity coefficient of water \\
\hline $\mathrm{P}_{\alpha}$ & Air pressure $(\mathrm{Pa})$ & $\mathrm{x}_{\mathrm{w}}$ & Mole fraction of water \\
\hline$P_{\text {avg }}$ & Average pressure of the membrane $(\mathrm{Pa})$ & & \\
\hline $\mathrm{P}_{\mathrm{w}}$ & Vapor pressure of pure water $(\mathrm{Pa})$ & Subscript & \\
\hline$P_{\text {reference }}$ & Reference pressure $(\mathrm{Pa})$ & $\mathrm{f}$ & Feed side \\
\hline$\alpha$ & Dimensionless coefficient ratio & $\mathrm{p}$ & Permeate side \\
\hline$Q$ & Heat flux $\left(\mathrm{kJ} / \mathrm{m}^{2} \cdot \mathrm{hr}\right)$ & $\mathrm{u}$ & Flow velocity $(\mathrm{m} / \mathrm{s})$ \\
\hline $\mathrm{h}$ & Heat transfer coefficient $\left(\mathrm{W} / \mathrm{m}^{2} \cdot \mathrm{K}\right)$ & $\mathrm{E}$ & Molecular diffusion \\
\hline
\end{tabular}




\begin{tabular}{|llll}
$\mathrm{A}$ & Thermal conductivity $(\mathrm{kW} / \mathrm{m} \cdot \mathrm{K})$ & $\mathrm{P}$ & Poiseuille flow diffusion \\
$\mathrm{L}$ & Membrane module length $(\mathrm{m})$ & $\mathrm{K}$ & Knudsen diffusion \\
$\rho$ & Fluid density $\left(\mathrm{kg} / \mathrm{m}^{3}\right)$ & $\mathrm{m}$ & Membrane surface \\
$\mathrm{Cp}$ & Specific heat capacity of fluid & $\mathrm{x}$ & Transversal (x-direction) \\
$\lambda$ & Latent heat of water & $\mathrm{z}$ & Axial (z-direction) \\
$\mathrm{R}$ & Membrane resistance $\left(\mathrm{Pa} \cdot \mathrm{m}^{2} \cdot \mathrm{h} / \mathrm{L}\right)$ & & \\
$\mathrm{R}$ & Time (s) & &
\end{tabular}

\section{Introduction}

In recent times, membrane distillation (MD) has gained wide attention as an alternative water treatment technology with a capability of treating and concentrating solutions with high salinity [1-4]. The main benefits of MD are the production of high quality permeate utilizing vapor driven force compared to pressure driven technologies and low thermal requirement compared to conventional thermal technologies $[2,5]$. On this basis of advantages of $\mathrm{MD}$, it has been regarded as a viable alternative concentrate treatment technology $[3,4]$.

Presently, many wastewater reclamation plants (WRPs) around the world are progressively using reverse osmosis (RO) technology as a final polishing step due to its capability to maintain a high grade water standard $[1,6]$. However, a substantially large volume of wastewater RO concentrate (ROC) is produced, generally comprising $20-25 \%$ of the feed stream volume [7]. For instance, two WRPs for biologically treated wastewater in New South Wales (Homebush bay and St. Marys WRPs) are using RO technology as a final treatment process. On a daily basis, around $2000 \mathrm{~kL}$ of water is treated by RO 
in Homebush bay WRP, resulting in $300 \mathrm{~kL} /$ day ROC while substantially larger volume of ROC (7000 $\mathrm{kL} /$ day) is produced from St.Marys WRP [8].

It has been well established that conventional methods such as coagulation and granular activated carbon (GAC) as well as advanced technologies such as, ozonation, electrochemical oxidation and photocatalysis are effective for treating ROC contaminants, specifically to reduce dissolved organics carbons as well as selective micro-pollutants prior to discharge from WRPs $[1,6,7]$. Nonetheless, these operations do not simultaneously reduce the ROC volume and its inorganic content.

In this regard, MD offers the possibility to concentrate pretreated ROC wastewater, while producing good quality distillate, making it a sustainable ROC treatment technology. Furthermore, the low salinity content of ROC wastewater (1-2 g/L), would enable MD to concentrate ROC to a high level. However, the aspect of scaling by the main ions such as $\mathrm{Ca}, \mathrm{Na}, \mathrm{SO}_{4}$, and $\mathrm{Cl}$ present in $\mathrm{ROC}$ wastewater must be given due consideration to establish the feasibility of MD operation for ROC wastewater treatment.

Direct contact membrane distillation (DCMD) is the most commonly used MD configuration due to its application simplicity [9]. In general, high feed temperature is used to achieve higher water production (water flux) in DCMD system [10]. At a high feed temperature, higher heat and mass transfer occur from the feed side, across the boundary layer and membrane, and to the permeate side. Large quantity of heat is used to vaporize the molecules at the membrane surface. It results in a significant conduction and latent heat-loss resulting in temperature difference between the bulk solution and membrane surface. This phenomenon is known as temperature polarization. Alternatively, a larger vapor driving pressure in DCMD can be created by incorporating a vacuum on the permeate side, even at relatively low feed temperature ranges. This is referred to as vacuum enhanced DCMD configuration (V-DCMD). The advantages of V-DCMD have been highlighted in previous literatures [11, 12]. Cath et al. [11] demonstrated that the V-DCMD system achieved a 15\% permeate flux increment (compared to DCMD) 
with the reduction of permeate side pressure (increased vacuum) from $108 \mathrm{kPa}$ to $94 \mathrm{kPa}$. Importantly, their study highlighted that on an economic aspect, the incorporation of vacuum did not incur significant additional cost due to the low pressure-gradient on the pump. Similarly, Naidu et al. [12] established the enhanced permeate flux performance of DCMD by $30 \%$ with reduced permeate pressure from 1000 mbar to 300 mbar using vacuum pump. However, this study observed a higher flux decline and fouling with V-DCMD compared to DCMD, even though a higher flux was attributed to the higher driving force in V-DCMD system.

Nevertheless, there are still limited researches on an in-depth understanding on the performance of a VDCMD in comparison to DCMD. Generally, the mass transfer across the membrane for DCMD system consist of Knudsen diffusion, molecular diffusion, surface diffusion, and viscous flow [13]. In this study, experimental data of V-DCMD and DCMD performance were used to estimate the transport mechanism and related resistance based on the empirical models and resistance coefficient values. An alpha coefficient was incorporated to represent the mass transfer scenario of V-DCMD. At the same time, a 2-D dynamic model temperature profile along the membrane module was used to compare the temperature profile of the DCMD and V-DCMD configuration. Further, the fouling profile was represented by coefficient values based on empirical fouling model. A continuous experimental operation of V-DCMD with membrane water flushing was carried out to verify the effectiveness of this configuration for ROC wastewater treatment. Membrane fouling pattern and its reversibility on membranes were analysed using scanning electron microscope - energy-dispersive spectroscopy (SEMEDX). 


\section{Materials and methods}

\subsection{Experimental set-up}

Experiments for DCMD and V-DCMD were carried out with the same effective membrane area of $0.0168 \mathrm{~m}^{2}(0.21 \mathrm{~m} \times 0.08 \mathrm{~m})$. The dimensions of membrane cell channel were $21.0 \mathrm{~cm}$ (length), $8.0 \mathrm{~cm}$ (width), and $0.4 \mathrm{~cm}$ (height). The membrane cell was designed to hold a flat sheet membrane securely in the membrane cell under moderate pressure gradients without the need for physical supports such as spacers (Fig. 1). A polytetrafluoroethylene (PTFE) flat-sheet hydrophobic membrane (General Electrics, US) was used in this study. The porosity, normalized pore size, and membrane thickness as provided by the supplier were $70-80 \%, 0.22 \mu \mathrm{m}$, and $179 \mu \mathrm{m}$, respectively. The DCMD baseline study (with deionized (DI) water) was carried out at different feed temperatures ranging from 50 to $65{ }^{\circ} \mathrm{C}$. Meanwhile the V-DCMD operation was carried out at different vacuum pressures (300 to $1000 \mathrm{mbar}$ ) at a feed temperature of $55{ }^{\circ} \mathrm{C}$. For all operating conditions, flow rate in both feed and permeate sides was $1.1 \mathrm{~L} / \mathrm{min}$, which corresponds to a cross-flow velocity of $0.06 \mathrm{~m} / \mathrm{s}$.

\subsection{Feed solution}

The baseline experiments were carried out with $1.5 \mathrm{~L}$ of DI water. To study the performance of DCMD and V-DCMD for the treatment of ROC wastewater, a synthetic solution $(1.5 \mathrm{~L})$ was used. The synthetic solution comprised of $600 \mathrm{mg} \mathrm{Na} / \mathrm{L}, 800 \mathrm{mg} \mathrm{Cl} / \mathrm{L}, 90 \mathrm{mg} \mathrm{Ca} / \mathrm{L}$ and $200 \mathrm{mg} \mathrm{SO} / \mathrm{L}$, emulating the characteristics of the major ions present in wastewater ROC from WRPs [8].

\subsection{Membrane characterization}

The morphology of fouled (tested) membrane and cleaned membrane was observed using Zeiss Supra 55VP field emission scanning electron microscope (FE-SEM). The membrane specimens were dried in a 
desiccator overnight prior to analysis. It was operated at $5 \mathrm{kV}$ in conjunction with Bruker XFlash silicon drift energy-dispersive spectroscopy (EDS) detector. The EDS analysis was used to obtain information on chemical characteristics of the membrane.

\section{Theory}

\subsection{Transfer mechanism in DCMD and V-DCMD}

\subsubsection{Mass transfer in DCMD}

The overall permeate water flux, J for DCMD can be calculated using Eq. (1):

$$
J=C\left(P_{f m} \quad P_{p m}\right)
$$

where, $\mathrm{C}$ is the mass transfer coefficient, which can be described by different models, $\mathrm{P}_{\mathrm{fm}}$ and $\mathrm{P}_{\mathrm{pm}}$ are the vapor pressures on the feed and permeate side membrane surface, respectively.

The $\mathrm{P}_{\mathrm{fm}}$ and $\mathrm{P}_{\mathrm{pm}}$ were calculated using the Antoine equation at the respective temperatures of $\mathrm{T}_{\mathrm{fm}}$ and $\mathrm{T}_{\mathrm{pm}}$, based on the Eq. (2) $[9,14]$ :

$$
P=\exp \left(23.7836 \frac{3782.89}{T \quad 42.85}\right)
$$

For non-ideal binary mixtures, the pressure can be determined by Eq. (3), while the water activity of water or other solutions such as $\mathrm{NaCl}, \gamma_{\mathrm{w}}$, were determined using the correlation equation (Eq. (4)). 


$$
P=x_{w} r_{w} P_{w}
$$

$r_{w}=1 \quad 0.5\left(1 \quad x_{w}\right) \quad 10\left(\begin{array}{ll}1 & x_{w}\end{array}\right)^{2}$

where, $x_{w}$ is the mole fraction of water, $\gamma_{w}$ is the activity coefficient of water, and $P_{w}$ is the vapor pressure of pure water.

Therefore in DCMD, mass transfer mechanism in the membrane is generally represented by the three mass diffusion models (Knudsen, molecular and Poiseuille) as described by Eq. (5) $[13,15]$ :

$$
J=\left(\frac{1}{J_{K}}+\frac{1}{J_{E}}\right)^{1}+J_{p}
$$

where, $\mathrm{J}_{\mathrm{K}}, \mathrm{J}_{\mathrm{E}}$ and $\mathrm{J}_{\mathrm{P}}$ are vapor flux from Knudsen, molecular, and Poiseuille flow diffusion and they can be calculated using Eqs. (6) to (8):

$$
J_{K}=C_{K} \quad P=1.064 \frac{r}{\sqrt{\frac{M}{R T}}}\left(P_{f i n} \quad P_{p m}\right)
$$

where, $J_{K}$ is the vapor flux through the membrane occurring from the Knudsen diffusion, $C_{K}$ is the Knudsen mass transfer coefficient, $\mathrm{r}$ is the membrane pore diameter, $\varepsilon$ is the membrane porosity, $\delta$ is the membrane thickness, $\tau$ is the membrane pore tortuosity, $\mathrm{M}$ is the molecular mass of water, and $\mathrm{R}$ is the universal gas constant. 


$$
J_{E}=C_{E} \quad P=\frac{P_{t o t a l} D_{W A}}{P_{a}} \frac{r}{\sqrt{\frac{M}{R T}}}\left(\begin{array}{ll}
P_{f m} & \left.P_{p m}\right)
\end{array}\right.
$$

where, $\mathrm{J}_{\mathrm{E}}$ is the vapor flux through the membrane arising from molecular flow, $\mathrm{C}_{\mathrm{E}}$ is the molecular mass transfer coefficient from molecular flow, $\mathrm{P}_{\text {total }}$ is the total pressure inside the pore (air pressure + water pressure), $\mathrm{P}_{\alpha}$ is the air pressure (assuming almost 1.0 atm), and $\mathrm{D}_{\mathrm{WA}}$ is the molecular diffusivity coefficient (subscripts ' $w$ ' and 'a' refer to water vapour and air).

$$
J_{P}=C_{P} \quad P=0.125 \frac{r^{2}}{R T} \frac{M P_{a v g}}{R T}\left(P_{f m} \quad P_{p m}\right)
$$

where, $\mathrm{J}_{\mathrm{p}}$ is the vapor flux through the membrane arising from Poiseuille flow, $\mathrm{C}_{\mathrm{P}}$ is the Poiseuille-flow mass transfer coefficient, $\mathrm{P}_{\mathrm{avg}}$ is the mean pressure of the membrane $\left(\mathrm{P}_{\mathrm{avg}}=\left(\mathrm{P}_{\mathrm{fm}}+\mathrm{P}_{\mathrm{pm}}\right) / 2\right)$, and $\eta$ is the water vapor viscosity.

\subsubsection{Mass transfer in V-DCMD}

V-DCMD mass diffusion model was represent by introducing a dimensionless coefficient ratio

( $\alpha$ ) based on the theory of Schofield et al. [16]. The $\alpha$ represented the membrane permeate pressure and was derived by using the average pressure between the bulk feed and permeate vacuum, and reference pressure, $\mathrm{P}_{\text {reference }}$ as presented in Eq. (9):

$\alpha=1-\left(\mathrm{P}_{\text {avg }} / \mathrm{P}_{\text {reference }}\right)$

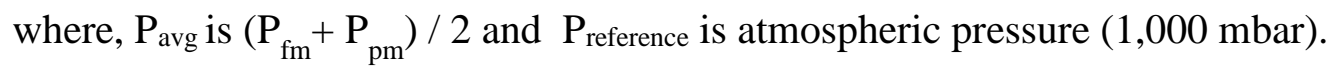


By adding the $\alpha$ value to Eq. (1), the permeate flux for V-DCMD can be calculated using Eq. (10) $[13,16]:$

$J=\quad C\left(P_{f m} \quad\left(\begin{array}{lll}P_{p m} & P_{p m} & ))\end{array}\right.\right.$

\subsection{Heat transfer and transport resistance}

Heat transfer in DCMD and V-DCMD can be considered in three steps: i) convective heat transfer from the heated feed solution across the boundary layer to the membrane surface $\left(Q_{f}=h_{f}\left(T_{f}-\right.\right.$ $\left.T_{f m}\right)$ ), ii) heat transfer across the membrane by conduction and heat assembling the vapor flow through the membrane pores $\left(Q_{m}=J H+h_{m}\left(T_{f m}-T_{p m}\right)\right)$, and iii) convective heat transfer from the membrane surface of the permeate side across the boundary layer to the bulk of permeate solution $\left(Q_{p}=h_{p}\left(T_{p m}\right.\right.$ $-T p))[9,13]$. The total heat transfer through the membrane, $\left(Q_{m}\right)$ in DCMD and V-DCMD is by conduction across the membrane pores and latent heat due to molecule vaporization.

In this study, a two-dimensional (2D) dynamic model for flat sheet module was used to represent

the heat transfer as presented by Shim et al. [15]. The model geometry represented the heat transfer of the feed and permeate channel thickness as FT and PT from 0 to 1 , with 1 being closer to the membrane. Similarly, the heat transfer through the feed and permeate channel length (FL and PL, respectively) were presented by channel inlet $(\mathrm{L}=0)$, centre $(\mathrm{L}=0.5)$ and outlet $(\mathrm{L}=1)$ as shown in Fig. 2 .

The following assumptions were used: (i) non steady-state, (ii) constant physical properties of fluids and membrane, (iii) incompressible hot and cold flow, (iv) negligible momentum of permeate flow through the membrane, (v) negligible heat loss to the ambient environment, (vi) negligible concentration polarization of the feed solution, (vii) no chemical reaction and (viii) negligible membrane fouling. To solve the 2-D dynamic model equations, the orthogonal collocation method and the variable 
coefficients ordinary differential equation integrator were used $[15,17,18]$. The main thermal equations with the initial and boundary conditions for representing the 2D dynamic model were expressed using Eqs. (11) to (16):

$\frac{T_{i}}{t}=\frac{A_{Z}}{C_{p}} \frac{{ }^{2} T_{i}}{z^{2}} \quad u_{i}(x) \frac{T_{i}}{z}+\frac{A_{x}}{C_{p}} \frac{{ }^{2} T_{i}}{z^{2}} \quad i=$ feed or permeate

$T_{i}\left(0, x_{i}, z\right)=T_{i, i n}$

$\left.A_{F} \frac{\partial T_{i}}{\partial x}\right|_{x=d i}= \pm\left(Q+A_{m} \frac{\left(T_{F} T_{P}\right)}{m}\right)$

$\left.\frac{T_{i}}{x}\right|_{x=0}=0$

$\left.A_{z} \frac{T_{i}}{z}\right|_{Z=0}=\quad C_{p} u_{i}\left(\left.\left.T_{i}\right|_{z=0} \quad T_{i}\right|_{z=0^{+}}\right)$

$\left.\frac{T_{i}}{z}\right|_{Z=L}=0$

where, $A_{z}, A_{x}, A_{m}, \rho, u, C_{p}, Q$, and $\lambda$ are the axial thermal conductivity of fluid, transversal thermal conductivity of fluid, thermal conductivity of membrane, fluid density, flow velocity and specific heat capacity of fluid, heat water flux and latent heat of water, respectively. 


\subsubsection{Transport resistance}

The resistance on the membrane was calculated from Eq. (17) $[11,19]$.

$R_{m}=\frac{P_{f m}}{J \bullet P_{p m}}=\frac{P_{(F T=1, F L=0.5)}}{J \bullet P_{(P T=1, P L=0.5)}}$

where, $\mathrm{J}$ is the water flux, $\mathrm{P}_{\mathrm{fm}}$ and $\mathrm{P}_{\mathrm{pm}}$ are the vapor pressure at the surface of membrane at feed and permeate sides. The vapour pressure at the membrane feed and permeate sides were derived from the average temperature profile values from the 2-D model.

\subsection{Flux decline coefficients}

The EFD model is a simple flux decline models where EFD coefficients can be evaluated from experimental results using nonlinear regression [20]. The equation, Eq.18 consists of three flux-decline coefficients $\left(\mathrm{k}_{0}, \mathrm{k}_{1}\right.$ and $\left.\mathrm{d}\right)$ :

$$
\frac{J_{t}}{J_{0}}=\frac{1}{1+k_{0}\left(1 e^{k_{1} t}\right)+d t}
$$

where, $k_{0}$ is the given flux decline potential, which is dimensionless, $k_{1}$ is the rate constant, which represents how quickly flux decline occurs, and $d$ is the flux decline kinetic constant. The unit of both $k_{1}$ and $d$ is $\min ^{-1}$. 


\section{Results and discussion}

\subsection{Transfer mechanism in DCMD and V-DCMD}

Transfer mechanisms in DCMD and V-DCMD were investigated using experimental data and mass diffusion model.

\subsubsection{DCMD mass transfer}

The DCMD performance was examined by varying the feed temperature from $50{ }^{\circ} \mathrm{C}$ to $65{ }^{\circ} \mathrm{C}$ (Table 1). The results showed a permeate flux increment of around 1.8 times $(9.0 \pm 0.2$ to $16.0 \pm 0.5$ $\mathrm{LMH}$ ) with a $15{ }^{\circ} \mathrm{C}$ of feed temperature increment. Permeate flux increased linearly with feed temperature (Fig. 3). This indicated that the feed temperature mainly contributed to higher diving force (larger vapour pressure gradient), increasing the mass transfer which corresponds to the high permeate flux pattern. Similar trends have been described in other studies $[9,14]$.

In DCMD, mass transfer can be divided into three steps: i) mass transfer in feed boundary layer, ii) mass transfer across the membrane, and iii) mass transfer in permeate boundary layer. Here, the mass transfer in permeate boundary layer is not taken into account since the mole fraction of the transporting species in the permeate stream is approximately equal to one. In addition, the essential models employed to describe the mass transfer across the hydrophobic porous membrane: a) viscous flow, b) Knudsen diffusion (due to the larger mean free path of vapor molecules than the membrane pore size), c) molecular diffusion (due to concentration gradient across the membrane) and d) Poiseuille flow model (due to the momentum transfer to the membrane area). The vapor molecule motions (comparison between the mean free path and pore diameter) are the distinction factor between these models. In DCMD configuration, viscous flow can be negligible, as both feed and permeate aqueous solutions are brought into contact with the membrane under atmospheric pressure, maintaining a constant total pressure at approximately $1 \mathrm{~atm}$ [13]. 
As can be seen from Fig. 3, the experimental flux fitted well with the calculated flux using the DCMD mass diffusion model based on Eq. (5).

\subsubsection{V-DCMD mass transfer}

A baseline study with DI water was conducted to analyse the effect of vacuum incorporation on the permeate side of the DCMD configuration (here, V-DCMD). Even at a feed temperature of $55^{\circ} \mathrm{C}$, an increase in permeate flux (approximately 1.4 times higher) was achieved in the V-DCMD operation as the permeate pressure reduced from 1000 to 300 mbar (Table 1).

The mass transfer mechanism of V-DCMD can be linked to the concept of deaerated DCMD system as described by previous researchers $[13,16,21]$. Based on their studies, it was deduced that a substantial flux increase can be achieved by degasing/deaerating the liquids in the DCMD system, creating a lower liquid pressure because MD membranes have larger pores than the mean free path of the water molecules. The presence of non-condensable gasses between the membrane surfaces hinders the diffusion of water vapor resulting in lower fluxes. By lowering the liquid pressure, the gas pressure/partial pressure within the membrane pores substantially reduced. Similarly, a study on air gap MD reported on achieving three times higher flux upon removing non-condensable gases [22]. In line with this, Schofield et al. [16] proposed an empirical model with Knudsen/Poiseuille transition for representing deaerated DCMD, where a coefficient value of dimensionless pressure $\left(\mathrm{P} / \mathrm{P}_{\text {ref }}\right)$ was incorporated in the flux equation.

In this study, for the first time, the theory of Schofield et al. [16] was applied to represent the scenario of V-DCMD mass diffusion model by introducing a $\alpha$, a dimensionless coefficient ratio to represent the membrane permeate pressure as presented in Eq. (9). Fig. 4 shows a good correlation between the $\alpha$ value and the permeate (bulk) pressure. The $\alpha$ value was incorporated to calculated the VDCMD permeate flux as presented in Eq. (10). Using Eq. (10), the V-DCMD fluxes at two different 
permeate vacuum pressures (260 and 200 mbar) were predicted (Fig. 5). This verified the model fitting to the experimental permeate flux.

In V-DCMD, it was possible to obtain more than $30 \%$ higher permeate flux in comparison to DCMD at the same feed temperature. This was attributed to the partial elimination of stagnant air from the pores, which effectively reduced the resistance for vapor diffusion across the membrane as well as increased convective mass transport in the pores by enhanced total pressure gradient in the pore [11]. In this condition (V-DCMD), the dominant mass transport was most likely Knudsen/Poiseuille transition and minimally molecular diffusion, as molecular diffusion depends on the partial pressure of air in the membrane pores and in the V-DCMD system, minimal air is present within the membrane pores [13]. On the other hand, the DCMD system mass transfer is a combination of Knudsen/Poiseuille as well as molecular diffusion. The resistance of water vapour diffusion through the membrane air pores in the DCMD most likely resulted in lower permeate flux compared to the V-DCMD. As such, the $\alpha$ coefficient represented the reduced partial pressure and increased vapour diffusion in V-DCMD.

\subsection{Heat transfer and transport resistance}

\subsubsection{Temperature profile}

In $\mathrm{V}$-DCMD, the partial elimination of stagnant air from the pores has been implied to reduce convection heat loss in the membrane [11]. To represent this phenomenon, in this study, a theoretical temperature distribution profile generated from the 2D model was used to represent the water vapor's heat transport mechanism in the V-DCMD (and the DCMD) (Fig. 2). To obtain an accurate temperature distribution profile, the experimental operation parameters used are as follows: feed temperature $\left(\mathrm{T}_{\mathrm{F}}\right)=$ $55^{\circ} \mathrm{C}$ and $65^{\circ} \mathrm{C}$, permeate temperature $\left(\mathrm{T}_{\mathrm{P}}\right)=25^{\circ} \mathrm{C}$, feed and permeate velocity $=0.06 \mathrm{~m} / \mathrm{s}$, membrane pore diameter $(r)=0.22 \mu \mathrm{m}$; counter current flow module; parabolic for laminar flow. 
Fig. 6 shows the temperature variation across and along the flow channels on the feed and permeate side at different feed temperature and vacuum pressures. Additionally, the temperature variation is presented in Fig. 7 as a line scatter for comparison of the temperature pattern between the different configurations. The temperature profiles were obtained at assumed steady state condition. Temperature boundary layers were evidently formed in both feed $(\mathrm{F})$ and permeate $(\mathrm{P})$ channels which became more prevalent as water flowed through the channels. At the channel inlet (entrance) (FT and $\mathrm{PT}=0$, and FL and PL $=0$ ), the water stream showed a uniform temperature distribution. As the water was channelled along the membrane, the evaporation of feed water reduced the temperature near the membrane (FT and FL $=1$ ), while the condensation of hot vapor on the permeate side increased the permeate stream temperature near the membrane $(\mathrm{PT}$ and $\mathrm{PL}=1)$. These created temperature gradients/boundary layers as can be evidently seen in Fig. 6 and Fig. 7, showing the feed and permeate temperature difference across the membrane, respectively.

A lower evaporation and condensation in DCMD (at $55^{\circ} \mathrm{C}$ and 1,000 mbar) resulted in a more uniform temperature distribution near the membrane (Fig. 6a). Specifically, across the membrane $(\mathrm{FT}=$ 0 to 1 ) of DCMD (at $55^{\circ} \mathrm{C}$ and 1000 mbar), $14.4{ }^{\circ} \mathrm{C}$ and $20.4{ }^{\circ} \mathrm{C}$ temperature difference occurred at FL $=0.5$ and FL $=1$, respectively (Fig. 7a). This represented the temperature losses near the membrane. Meanwhile in V-DCMD (at $55^{\circ} \mathrm{C}$ and 300 mbar), an increased mass transfer (higher evaporation and condensation) may have resulted in slightly higher temperature variation near the membrane (lower membrane feed temperature and a higher membrane permeate temperature) (Fig. 6b). Specifically, across the membrane (FT $=0$ to 1 ), for $\mathrm{V}$-DCMD (at $55{ }^{\circ} \mathrm{C}$ and 300 mbar), $16.7{ }^{\circ} \mathrm{C}$ and $22.9{ }^{\circ} \mathrm{C}$ temperature difference occurred at $\mathrm{FL}=0.5$ and $\mathrm{FL}=1$, respectively (Fig. 7a). The results showed that, at the same feed temperature of $55^{\circ} \mathrm{C}$, V-DCMD (300 mbar) could achieve at least $30 \%$ higher flux 
increment compared to DCMD with only slightly higher heat transfer losses compared to 1,000 mbar, establishing the advantages of vacuum incorporation to DCMD.

Likewise, in DCMD operation, to obtain the similar permeate flux $(16.0 \pm 0.5 \mathrm{LMH})$ as that of $\mathrm{V}$ DCMD (at $55^{\circ} \mathrm{C}$ and 300 mbar), a higher DCMD feed temperature setting $\left(65^{\circ} \mathrm{C}\right.$ ) had to use at 1,000 mbar. At the same time, a number of MD studies have carried out detailed energy evaluation. These studies have reported energy consumption in the range of 65-90 W for low vacuum consumption (200300 mbar) [23, 24]. On the other hands, Criscuoli et al. [25] reported a 200-220 W increment in energy consumption with an increase of the feed temperature by $20^{\circ} \mathrm{C}$ in a DCMD system.

Further, at this DCMD condition $\left(65^{\circ} \mathrm{C}\right.$ and 1000 mbar), an increased mass diffusion at higher feed temperature had likely resulted in elevated resistance (air pores resistance) at the membrane surface. Significant temperature loss appeared to have occurred near the membrane surface due to latent and conduction heat loss (Fig. 6c) as compared to V-DCMD (at 300 mbar and $55^{\circ} \mathrm{C}$ ). Specifically, for $\operatorname{DCMD}$ (at $65^{\circ} \mathrm{C}$ and 1000 mbar), across the membrane (FT $=0$ to 1$), 19.1{ }^{\circ} \mathrm{C}$ and $27.2^{\circ} \mathrm{C}$ temperature difference occurred at $\mathrm{FL}=0.5$ and $\mathrm{FL}=1$ (Fig. 7b). It is worth highlighting that the higher permeate flux achieved with V-DCMD was attributed to both higher driving force and removal of noncondensable gases. However, fast velocities in feed and permeate side can be reduced the effect of noncondensable gases. Further investigations must be carried out to identify the more significant flux increment contributor between these two factors.

\subsubsection{Transport resistance}

In MD process, the transport resistance consists of i) feed boundary layer resistance, ii) permeate boundary layer resistance and iii) membrane resistance $\left(\mathrm{R}_{\mathrm{m}}\right)$ (without the presence of fouling layer). In DCMD system, resistance in feed boundary layer is associated to temperature polarization effect and at 
higher feed temperature, this effect becomes more prevalent, enhancing feed boundary layer resistance. Contrarily, a higher feed temperature (higher driving force) will reduce membrane resistance, as resistance in membrane surface is associated with pore resistance across the membrane surface which is proportional to vapour molecular diffusivity. Vapour molecular diffusion is a function of driving force [19]. For this reason, at similar feed temperature of $55{ }^{\circ} \mathrm{C}, \mathrm{R}_{\mathrm{m}}$ is a useful indicator to compare the transport resistance of DCMD and V-DCMD as presented in Eq. (17).

In DCMD (1,000 mbar), increased feed temperature from $55^{\circ} \mathrm{C}$ to $65^{\circ} \mathrm{C}$, resulted in reduced $\mathrm{R}_{\mathrm{m}}$ from $0.030 \pm 0.001 \mathrm{~Pa} \cdot \mathrm{m}^{2} . \mathrm{h} / \mathrm{L}$ to $0.020 \pm 0.003 \mathrm{~Pa} \cdot \mathrm{m}^{2} . \mathrm{h} / \mathrm{L}$ (Table 2). This is related to the higher driving force at higher temperature on the membrane surface, increasing the vapour molecular diffusion. Meanwhile, at similar feed temperature of $55{ }^{\circ} \mathrm{C}$, a significantly lowered $\mathrm{R}_{\mathrm{m}}$ value $(0.005 \pm 0.002$ Pa.m².h/L) was achieved with V-DCMD (at 300 mbar), compared to DCMD (at 1000 mbar), clearly indicating the lower resistance/hindrance of vapor molecular diffusion through membrane in V-DCMD configuration. The reduction of air/gas pressure within the pores of the membrane coupled with higher driving force by incorporating the vacuum, would result in lower hindrances of molecular diffusion and increased diffusion through the membrane pores. This would enhance the permeate flux in the VDCMD, verifying the concept discussed in Section 3.2. Overall, the results of the transport mechanism and temperature profile established the advantages of V-DCMD over DCMD.

\subsection{Flux decline coefficients}

Several studies employed the blocking filtration laws proposed by Hermia [26] to describe fouling behaviour for dead-end filtration mode. Hermia's model has been applied for cross flow mode application with some modification [27, 28]. A previous DCMD study showed that fouling with a mixture of humic and calcium feed solution corresponded well to Hermia's cake filtration model [19]. 
Experiments were carried out with three different feed solutions of i) $\mathrm{NaCl}$ alone, and ii) $\mathrm{NaCl}$ with $\mathrm{CaSO}_{4}$ representing constituents of wastewater ROC. The permeate flux at different times (DCMD transport mechanism). However, Hermia's blocking filtration models did not fit well to the experimental data obtained in this study. This could be because rapid fouling occurs in MD when the membrane surface (or pore) was blocked, which was the main difference between MD compared to other membrane processes. Ramezanianpour and Sivakumar [28] highlighted that the permeate flux decline in MD processes does not show the first order exponential decay generally represented for other membrane processes.

On the other hand, the experimental fouling flux profiles of V-DCMD (at 300 mbar) and DCMD (at 1000 mbar) were fitted well with the emperical flux decline model (EFD) used in the study (Eq. (18)) as presented in Fig. 8. Three flux-decline coefficients ( $\mathrm{k}_{0}, \mathrm{k}_{\mathrm{l}}$, and d) were obtained by fitting experimental and simulated plots. Two flux-decline coefficients ( $\mathrm{d}$ and $\mathrm{k}_{0}$ ) show the total qualitative capacity of flux decline through the correlation analysis results. The coefficient $\mathrm{k}_{1}$ represents a kinetic flux-decline trend. A sensitivity test showed that the coeffient $\mathrm{k}_{1}$ was the most sensitive with the changes of its reference value $(\operatorname{Ref}=1.0)\left(\right.$ Fig. 9). No changes were observed with $k_{0}$ and $d$ coefficient values. The $\mathrm{k}_{1}$ value showed a good relationship with the flux ratio $\left(\mathrm{J} / \mathrm{J}_{0}\right)$ with a inverse pattern of $\mathrm{k}_{1}$ value with $\mathrm{J} / \mathrm{J}_{0}$ ratio (Table 3). Thus, $\mathrm{k}_{1}$ value is a good indicator to determine the flux decline in the MD process.

At $\mathrm{F}_{\mathrm{t}}$ of $55^{\circ} \mathrm{C}$, both DCMD (1000 mbar) and V-DCMD (300 mbar) showed a closely similar flux decline ratio, between the ranges of 0.73 to 0.82 , for all feed solutions (Fig. 8 and Table 3). In fact, the V-DCMD achieved slightly lower flux decline ratio than DCMD. This could probably be related to the low inorganic concentration of the wastewater ROC feed solution and operating at low feed temperature, resulting in low scaling development, which minimally influenced the flux pattern. Hence, in these operating conditions, the slight flux decline occurrence could be attributed to $\mathrm{NaCl}$ concentration 
polarization effect that increased the mass transfer resistance across the membrane. The lower flux decline ratio of the V-DCMD could therefore be attributed to its efficient mass transfer and lower membrane resistance compared to DCMD. In line with this, Martinetti et al. [29] observed only slightly higher flux decline with V-DCMD (480 mbar) compared to V-DCMD (880 mbar) at a temperature gradient of $20^{\circ} \mathrm{C}$ for treating saline reverse osmosis brine containing ions such as $\mathrm{Ca}$ and $\mathrm{Mg}$. On the other hand, at a temperature gradient of $40{ }^{\circ} \mathrm{C}$, a significant flux decline was observed at these respective vacuum pressures and with saline brine containing higher ion contents; verifying that a higher temperature gradient and presence of high ion contents are the main contributing factors for flux decline related to scaling in V-DCMD.

\subsection{Continuous V-DCMD operation for ROC wastewater}

A continuous operation of V-DCMD was carried out with a synthetic ROC wastewater solution (2.2 $\mathrm{g} / \mathrm{L})$ to validate a lower fouling tendency in V-DCMD. Only a $25-29 \%$ flux decline was observed even when the initial volume of feed solution reduced by a fourth (volume concentration factor, $\mathrm{VCF}=$ 4.0) (Fig. 10a). Thereafter, the membrane in V-DCMD was rinsed with DI water (100 mL) for removing salts deposited on the membrane surface, followed by another $\left(2^{\text {nd }}\right)$ cycle of V-DCMD operation with same synthetic ROC wastewater. The test was done for three cycles and each cycle lasted for $4 \mathrm{~h}$. The TDS concentration in permeate remained constantly low at 8 to $10 \mu \mathrm{S} / \mathrm{cm}$ (more than $98 \%$ removal) throughout the operation. This indicates that V-DCMD produced a good quality of permeate with a short DI water flushing. At the end of the operation (after finishing the $3^{\text {rd }}$ cycle), SEM-EDX analyses on the membranes before and after cleaning were carried out. The inorganic ions of $\mathrm{Ca}, \mathrm{S}$ and $\mathrm{NaCl}$ (salt) were presented on the used membrane while minimal ions were detected on the membrane after the cleaning

(Fig. 10b). As V-DCMD process is not a pressure-operated system, the inorganic crystals did not 
strongly adhere onto the MD membrane. Hence, with simple DI water flushing, most of the salts deposited on the membrane were removed as observed in Fig. 10b. The flux was restored in the subsequent experiments (with DI water flushing), suggesting that the flux decline most probably was attributed to concentration polarization effect and scaling was mostly reversible in V-DCMD operation. Similar trends of evolving flux decline with time associated with an increased Na concentration in the feed solution have been observed in other MD studies $[28,30]$. Therefore, this present study established the effectiveness of V-DCMD for producing good quality water while reducing the volume of ROC wastewater. 


\section{Conclusions}

The performance of V-DCMD (operated under vacuum pressure applied at the permeate side) was evaluated in terms of transport mechanism and fouling analysis. This study showed that the V-DCMD is a more promising option compared to the DCMD (operated under atmospheric pressure) due to following advantages:

- The V-DCMD (300 mbar) enhanced the permeate flux by $37.6 \%$ compared to the DCMD configuration at the same feed temperature $\left(55^{\circ} \mathrm{C}\right)$. This may be due to the reduced partial pressure in the pores of the membrane as well as the removal of non-condensable gases within the membrane pores, enabling a higher diffusion of water vapor through the membrane;

- $\quad$ The V-DCMD mass transport mechanism was explained by incorporating a dimensionless coefficient $(\alpha)$ into the empirical DCMD mass transport model;

- The simulated temperature profile distribution showed a reduced temperature loss in the VDCMD compared to the DCMD, which indicated a better energy efficiency in the V-DCMD configuration;

- In terms of projected energy consumption, for achieving a similar permeate flux of $16.0 \pm 0.3$ $\mathrm{LMH}, \mathrm{V}-\mathrm{DCMD}$ (at $55^{\circ} \mathrm{C}$ and $300 \mathrm{mbar}$ ) would theoretically require less energy consumption than DCMD (at $65^{\circ} \mathrm{C}, 1,000$ mbar);

- The V-DCMD showed a lower membrane resistance compared to the DCMD. This was associated with reduced resistance of water vapor diffusion through the membrane pores in the V-DCMD;

- $\quad$ The fouling profile of the V-DCMD was well represented by empirical flux decline model;

- V-DCMD operation was able to maintain a stable flux in continuous operation of ROC wastewater solution, enabling to produce good quality distillate while reducing the ROC volume. 
The permeate flux was recovered upon flushing the membrane with DI water which removed most salts deposited on the membrane (as observed in the EDX analysis). This reflected the suitability of V-DCMD application for ROC produced from wastewater reclamation plant.

\section{Acknowledgement}

This study was funded by the Cooperative Research Centre for Contamination Assessment and

Remediation of the Environment (CRC CARE) (Sustainable process for treatment of WWROC to achieve near zero liquid discharge). 


\section{References}

[1] A. Pérez-González, A.M. Urtiaga, R. Ibáñez, I. Ortiz, State of the art and review on the treatment technologies of water reverse osmosis concentrates, Water Res. 46(2) (2012) 267-283.

[2] A. Alkhudhiri, N. Darwish, N. Hilal, Membrane distillation: A comprehensive review, Desalination 287 (2012) 2-18.

[3] G. Naidu, Y. Choi, S. Jeong, T.M. Hwang, S. Vigneswaran, Experiments and modeling of a vacuum membrane distillation for high saline water, J. Ind. Eng. Chem. 20(4) (2014) 2174-2183.

[4] J. Xu, Y.B. Singh, G.L. Amy, N. Ghaffour, Effect of operating parameters and membrane characteristics on air gap membrane distillation performance for the treatment of highly saline water, J. Membr. Sci. 512 (2016) 73-82.

[5] N. Ghaffour, J. Bundschuh, H. Mahmoudi, M.F.A. Goosen, Renewable energy-driven desalination technologies: a comprehensive review on challenges and potential applications of integrated systems, Desalination 356 (2014) 94-114.

[6] L.S. Tam, T.W. Tang, G.N. Lau, K.R. Sharma, G.H. Chen, A pilot study for wastewater reclamation and reuse with MBR/RO and MF/RO systems, Desalination 202(1-3) (2007) 106113.

[7] A.Y. Bagastyo, J. Keller, Y. Poussade, D.J. Batstone, Characterisation and removal of recalcitrants in reverse osmosis concentrates from water reclamation plants, Water Res. 45(7) (2011) 2415-2427.

[8] S. Shanmuganathan, T.V. Nguyen, S. Jeong, J. Kandasamy, S. Vigneswaran, Submerged membrane-(GAC) adsorption hybrid system in reverse osmosis concentrate treatment, Sep. Purif. Technol. 146 (2015) 8-14. 
[9] M. Qtaishat, T. Matsuura, B. Kruczek, M. Khayet, Heat and mass transfer analysis in direct contact membrane distillation, Desalination 219(1) (2008) 272-292.

[10] A.M. Alklaibi, N. Lior, Membrane-distillation desalination: status and potential, J. Membr. Sci. 282(1) (2006) 362-369.

[11] T.Y. Cath, V.D. Adams, A.E. Childress, Experimental study of desalination using direct contact membrane distillation: a new approach to flux enhancement, J. Membr. Sci. 228(1) (2004) 5-16.

[12] G. Naidu, S. Jeong, S. Vigneswaran, E. K. Jang, Y. J. Choi, T. M. Hwang, Fouling study on vacuum-enhanced direct contact membrane distillation for seawater desalination, Desalin. Water Treat. (2015) 1-10.

[13] M. Khayet, Membranes and theoretical modeling of membrane distillation: A review, Adv. Colloid Interface Sci. 164(1-2) (2011) 56-88.

[14] T.C. Chen, C.D. Ho, H.M. Yeh, Theoretical modeling and experimental analysis of direct contact membrane distillation, J. Membr. Sci. 330 (2009) 279-287.

[15] W.G. Shim, K. He, S. Gray, I.S. Moon, Solar energy assisted direct contact membrane distillation (DCMD) process for seawater desalination, Sep. Purif. Technol. 143 (2015) 94-104.

[16] R.W. Schofield, A.G. Fane, C.J.D. Fell, Gas and vapour transport through microporous membranes. I. Knudsen-Poiseuille transition, J. Membr. Sci. 53(1-2) (1990) 173-185.

[17] J. Viladsen, M.L. Michelson, Solution of Differential Equation Models by Polynomial ApproximationPrentice-Hall, Englewood Cliffs, New Jersey (1978)

[18] P. N. Brown, G. D. Byrne, A. C. Hindmarsh, VODE: A variable-coefficient ODE solver, SIAM J. Sci. Statist. Comput. 10 (1989) 1038-1051.

[19] S. Srisurichan, R. Jiraratananon, A. G. Fane, Mass transfer mechanisms and transport resistances in direct contact membrane distillation process, J. Membr. Sci. 277(1-2) (2006) 186-194. 
[20] J. Cho, Natural organic matter (NOM) rejection by flux-decline of nanofiltration (NF) and ultrafiltration (UF) membranes. PhD dissertation, Department of Civil, Environmental, and Architectural Engineering, University of Colorado at Boulder, 1998.

[21] A.G. Fane, R.W. Schofield, C. J. D. Fell, The efficient use of energy in membrane distillation, Desalination 64(0) (1987) 231-243.

[22] A.S. Alsaadi, L. Francis, H. Maab, G.L. Amy, N. Ghaffour, Evaluation of air gap membrane distillation process running under sub-atmospheric conditions: Experimental and simulation studies, J. Membr. Sci. 489 (2015) 73-80.

[23] R. Sarbatly, C. Chiam, Evaluation of geothermal energy in desalination by vacuum membrane distillation, Appl. Energy. 112 (2013) 737-746.

[24] M. Safavi, T. Mohammadi, High-salinity water desalination using VMD, Chem. Eng. J. 149 (2009) 191-195.

[25] A. Criscuoli, M.C. Carnevale, E. Drioli, Evaluation of energy requirements in membrane distillation, Chemical Engineering and Processing: Process Intensification. 47 (2008) 1098-1105

[26] J. Hermia, Constant pressure blocking filtration law application to powder-law non-Newtonian fluid, Trans. IChemE. 60 (1982) 183-187.

[27] M.C. Vincent Vela, S. Álvarez Blanco, J. Lora García, E. Bergantiños Rodríguez, Analysis of membrane pore blocking models adapted to crossflow ultrafiltration in the ultrafiltration of PEG, Chem. Eng. J. 149(1-3) (2009) 232-241.

[28] M. Ramezanianpour, M. Sivakumar, An analytical flux decline model for membrane distillation, Desalination 345 (2014) 1-12.

[29] C. R. Martinetti, A. E. Childress, T. Y. Cath, High recovery of concentrated RO brines using forward osmosis and membrane distillation, J. Membr. Sci. 331 (2009) 31-39. 
[30] C.M. Tun, A.G. Fane, J.T. Matheickal, R. Sheikholeslami, Membrane distillation crystallization of concentrated salts—flux and crystal formation, J. Membr. Sci. 257 (2005) 144-155. 


\section{List of Tables}

Table 1 Permeate fluxes of DCMD and V-DCMD (feed and permeate= DI water, feed and permeate velocity $=0.06 \mathrm{~m} / \mathrm{s}$, permeate temperature $25^{\circ} \mathrm{C}$ ).

Table 2 Comparison of fluxes and membrane resistances of DCMD and V-DCMD.

Table 3 Comparison of flux decline ratio $\mathrm{J} / \mathrm{J}_{0}$ with flux decline coefficient value. 
Table 1 Permeate fluxes of DCMD and V-DCMD (feed and permeate= DI water, feed and permeate velocity $=0.06 \mathrm{~m} / \mathrm{s}$, permeate temperature $25^{\circ} \mathrm{C}$ ).

\begin{tabular}{|c|c|c|c|c|}
\hline \multirow{3}{*}{$\begin{array}{l}\text { Permeate vacuum } \\
\text { pressure (mbar) }\end{array}$} & \multicolumn{4}{|c|}{ Permeate Flux (LMH) } \\
\hline & \multicolumn{4}{|c|}{ Average feed temperature $\left({ }^{\circ} \mathrm{C}\right)$} \\
\hline & 50 & 55 & 60 & 65 \\
\hline 1,000 (no vacuum) & $9.0 \pm 0.2$ & $11.0 \pm 0.9$ & $14.0 \pm 0.2$ & $16.0 \pm 0.5$ \\
\hline 800 & - & $13.0 \pm 0.4$ & - & - \\
\hline 600 & - & $14.0 \pm 0.8$ & - & - \\
\hline 300 & - & $16.0 \pm 0.3$ & - & - \\
\hline
\end{tabular}


Table 2 Comparison of permeate fluxes and membrane resistances of DCMD and V-DCMD.

\begin{tabular}{lllll}
\hline Configuration & Feed Temperature $\left({ }^{\circ} \mathrm{C}\right)$ & Permeate pressure $(\mathrm{mbar})$ & Flux $(\mathrm{LMH})$ & $\mathrm{R}_{\mathrm{m}}\left(\mathrm{Pa} \cdot \mathrm{m}^{2} . \mathrm{h} / \mathrm{L}\right)$ \\
\hline DCMD & 55 & 1000 & $11.0 \pm 0.9$ & $0.030 \pm 0.001$ \\
DCMD & 65 & 1000 & $16.0 \pm 0.5$ & $0.020 \pm 0.003$ \\
V-DCMD & 55 & 300 & $16.0 . \pm 0.3$ & $0.005 \pm 0.002$ \\
\hline
\end{tabular}


Table 3 Comparison of flux decline ratio $\mathrm{J} / \mathrm{J}_{0}$ with flux decline coefficient value.

\begin{tabular}{llll}
\hline MD configuration & Feed solution & $\mathrm{J} / \mathrm{J}_{0}$ & $\mathrm{k}_{1}$ \\
\hline \multirow{2}{*}{$\mathrm{NCMD}(1000$ mbar $)$} & $\mathrm{NaCl}$ & 0.78 & $-6.41 \mathrm{E}-04$ \\
& $\mathrm{NaCl}+\mathrm{CaSO}_{4}$ & 0.73 & $-9.79 \mathrm{E}-02$ \\
\cline { 2 - 4 } & $\mathrm{NaCl}$ & 0.82 & $-6.93 \mathrm{E}-03$ \\
V-DCMD (300mbar) & $\mathrm{NaCl}+\mathrm{CaSO}_{4}$ & 0.74 & $-3.23 \mathrm{E}-02$ \\
\hline
\end{tabular}




\section{List of Figures}

Fig. 1. Experimental setup of (a) DCMD and (b) V-DCMD: (1) feed electronic balance (2) feed tank (3) heating blanket (4) feed tank temperature sensor (5) feed pump (6) feed flow-meter gauge (7) feed inlet pressure gauge (8) membrane module (9) feed outlet (brine) temperature sensor (10) brine (11) permeate electronic balance (12) permeate tank (13) cooling water (14) cooling unit (15) cooling pump (16) cooling flow-meter gauge (17) cooling water inlet temperature sensor (18) cooling water outlet temperature sensor (19) cooling water outlet pressure gauge (20) permeate (21) vacuum pump.

Fig. 2. 2D model of simulated DCMD with counter current flow across the membrane, with feed and permeate membrane channel thickness, FT and PT from scale 0 to 1 ( 0 being furthest (do you mean farest?) from the membrane, 1 being closest to the membrane) and channel length, FL and PL, where $\mathrm{L}=0$ (channel inlet), $\mathrm{L}=0.5$ (centre) and $\mathrm{L}=1$ (outlet).

Fig. 3. DCMD permeate flux as a function of feed temperature (feed and permeate $=$ DI water, feed and permeate velocity $=0.06 \mathrm{~m} / \mathrm{s}$, permeate temperature $=25^{\circ} \mathrm{C}$, and permeate pressure $=1000$ mbar).

Fig. 4. Correlation between the $\alpha$ value and the permeate pressure.

Fig. 5. V-DCMD experimental and modelling permeate flux as a function of vacuum pressure (feed water $=$ DI water, feed and permeate velocity $=0.06 \mathrm{~m} / \mathrm{s}$, feed temperature $=55^{\circ} \mathrm{C}$, and permeate temperature $=25^{\circ} \mathrm{C}$ ).

Fig. 6. Temperature distribution profile along the membrane module channel length and thickness of feed and permeate side of V-DCMD (300 mbar) and DCMD (1000 mbar) at $\mathrm{F}_{\mathrm{t}}$ of $55{ }^{\circ} \mathrm{C}$ and $65{ }^{\circ} \mathrm{C}$. (channel thickness, from scale 0 to 1 ( 0 being furthest from the membrane, 1 being closest to the membrane; and channel length, from scale $0=$ inlet, $1=$ outlet). 
Fig. 7. Line scatter of temperature distribution profile along the feed and permeate side membrane channel length (FL and PL) and thickness (FT and PT) of (a) V-DCMD (300 mbar) and DCMD (1000 mbar) at $\mathrm{F}_{\mathrm{t}}$ of $55^{\circ} \mathrm{C}$ (b) V-DCMD (300 mbar) and DCMD (1000 mbar) at $\mathrm{F}_{\mathrm{t}}$ of $55^{\circ} \mathrm{C}$ and $65^{\circ} \mathrm{C}$.

(channel thickness, from scale 0 to 1 (0 being furthest from the membrane, 1 being closest to the membrane; and channel length, from scale $0=$ inlet, $1=$ outlet .

Fig. 8. Experimental and modelling data of the flux decline of DCMD (1000mbar, $\left.\mathrm{F}_{t}=55^{\circ} \mathrm{C}\right)$ and $\mathrm{V}$ DCMD (300mbar, $\mathrm{F}_{\mathrm{t}}=55^{\circ} \mathrm{C}$ ) as a function of time and VCF with feed solutions of (a) $\mathrm{NaCl}$, and (b) $\mathrm{NaCl}$ with $\mathrm{CaSO}_{4}$.

Fig. 9. Sensitivity test for coefficients of (a) $\mathrm{k}_{0}$, (b) $\mathrm{k}_{1}$, and (c) $\mathrm{d}$ (Ref $=1.0$ with increment and decrement of $25 \%$ ).

Fig. 10. Continuous operation of V-DCMD for ROC wastewater treatment: (a) permeate flux with intermittent membrane cleaning, and (b) SEM-EDX of used membrane and membrane after DI water flushing. 
(a)

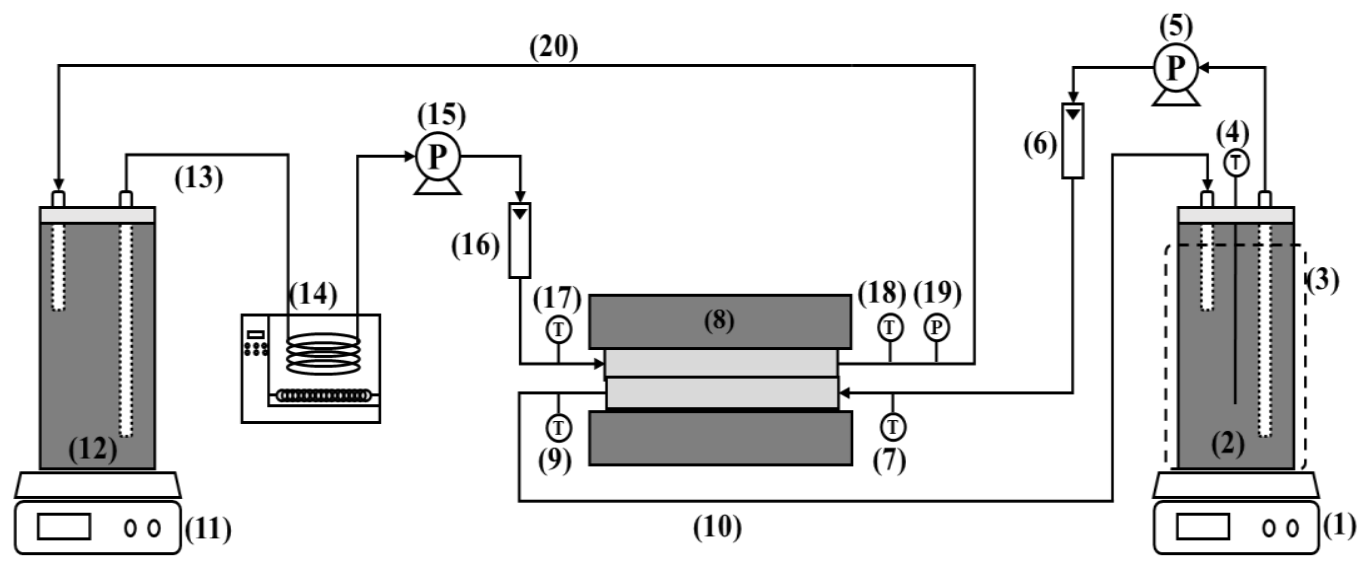

(b)

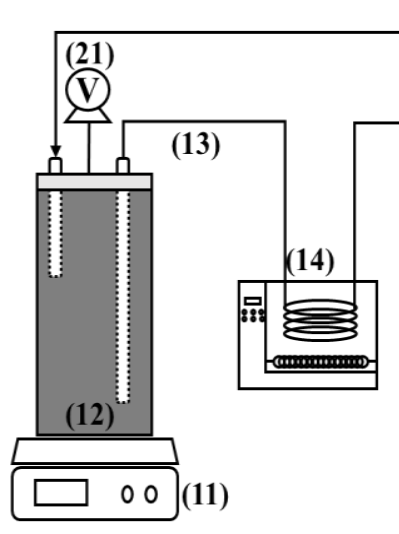

(20)
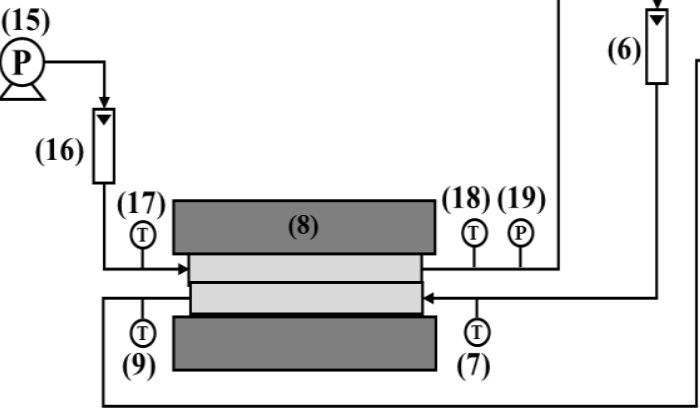

(10)

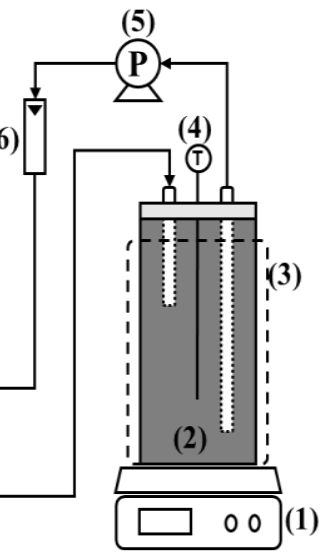

Fig. 1. Experimental setup of (a) DCMD and (b) V-DCMD: (1) feed electronic balance (2) feed tank (3) heating blanket (4) feed tank temperature sensor (5) feed pump (6) feed flow-meter gauge (7) feed inlet pressure gauge (8) membrane module (9) feed outlet (brine) temperature sensor (10) brine (11) permeate electronic balance (12) permeate tank (13) cooling water (14) cooling unit (15) cooling pump (16) cooling flow-meter gauge (17) cooling water inlet temperature sensor (18) cooling water outlet temperature sensor (19) cooling water outlet pressure gauge (20) permeate (21) vacuum pump. 


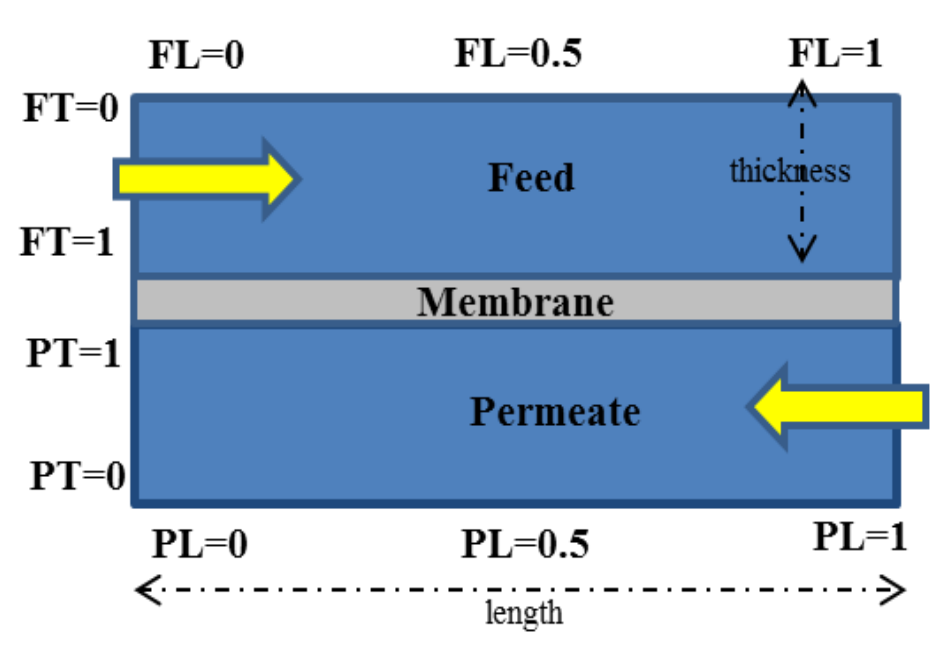

Fig. 2. 2D model of simulated DCMD with counter current flow across the membrane, with feed and permeate membrane channel thickness, FT and PT from scale 0 to 1 ( 0 being furthest from the membrane, 1 being closest to the membrane) and channel length, FL and PL, where $\mathrm{L}=0$ (channel inlet), $\mathrm{L}=0.5$ (centre) and $\mathrm{L}=1$ (outlet). 


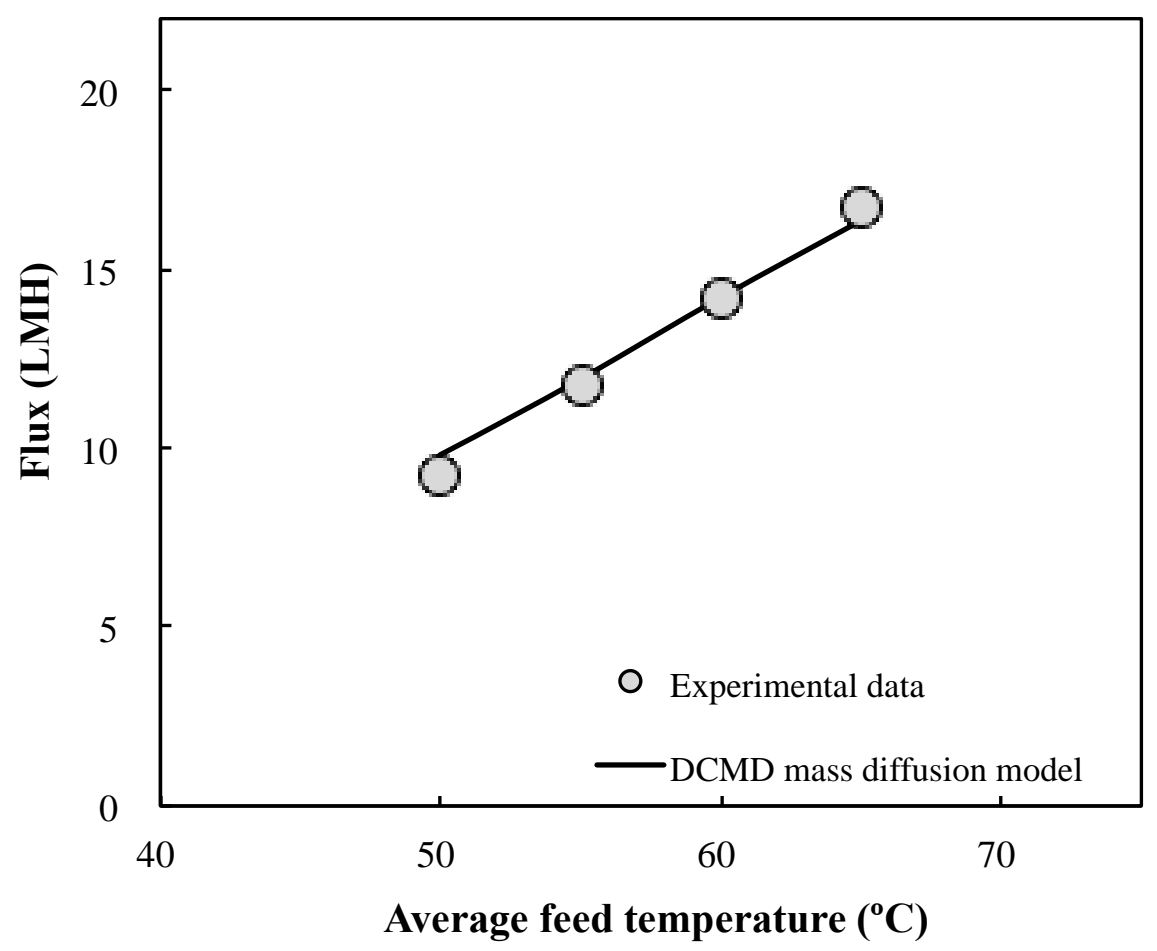

Fig. 3. DCMD permeate flux as a function of feed temperature (feed and permeate = DI water, feed and permeate velocity $=0.06 \mathrm{~m} / \mathrm{s}$, permeate temperature $=25^{\circ} \mathrm{C}$, and permeate pressure $=1000 \mathrm{mbar}$ ) . 


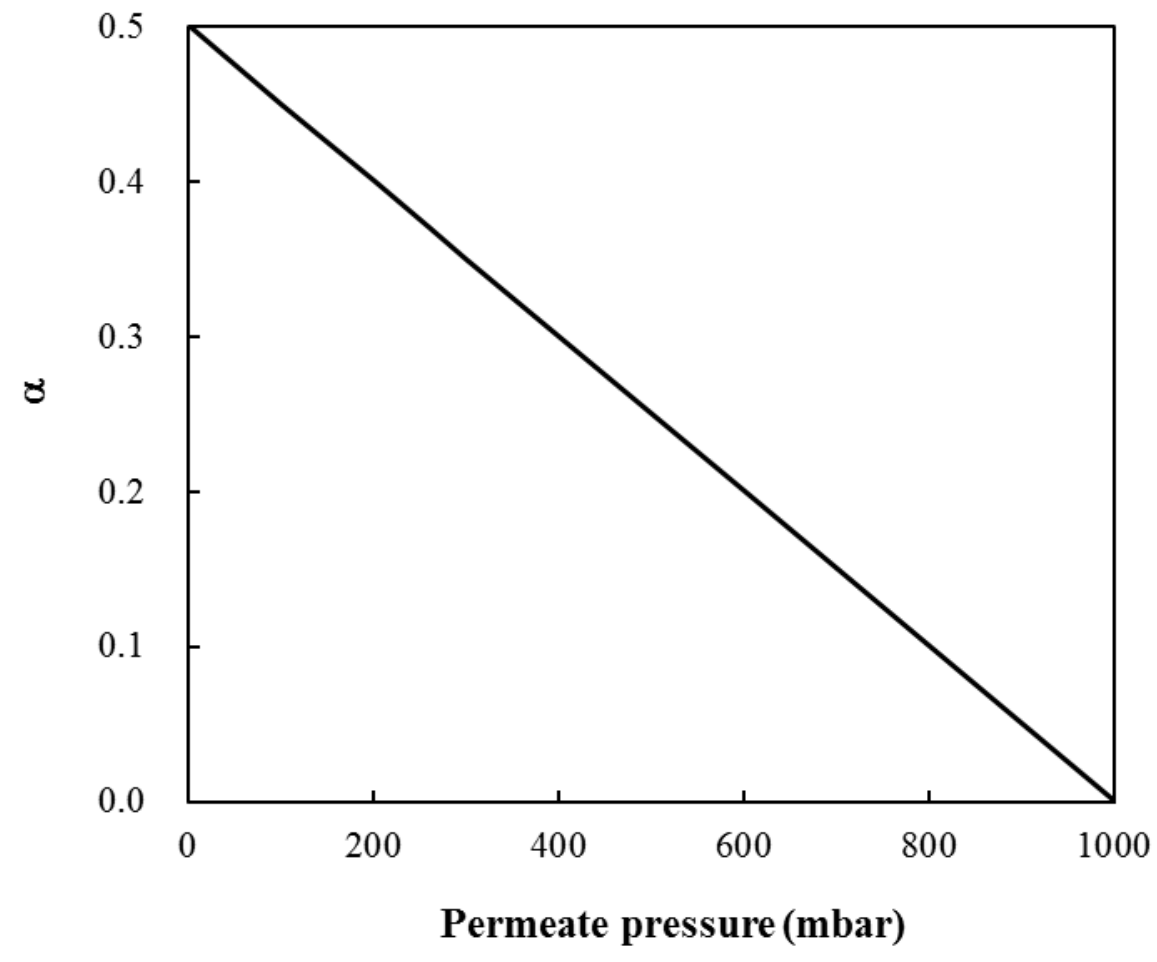

Fig. 4. Correlation between the $\alpha$ value and the permeate pressure. 


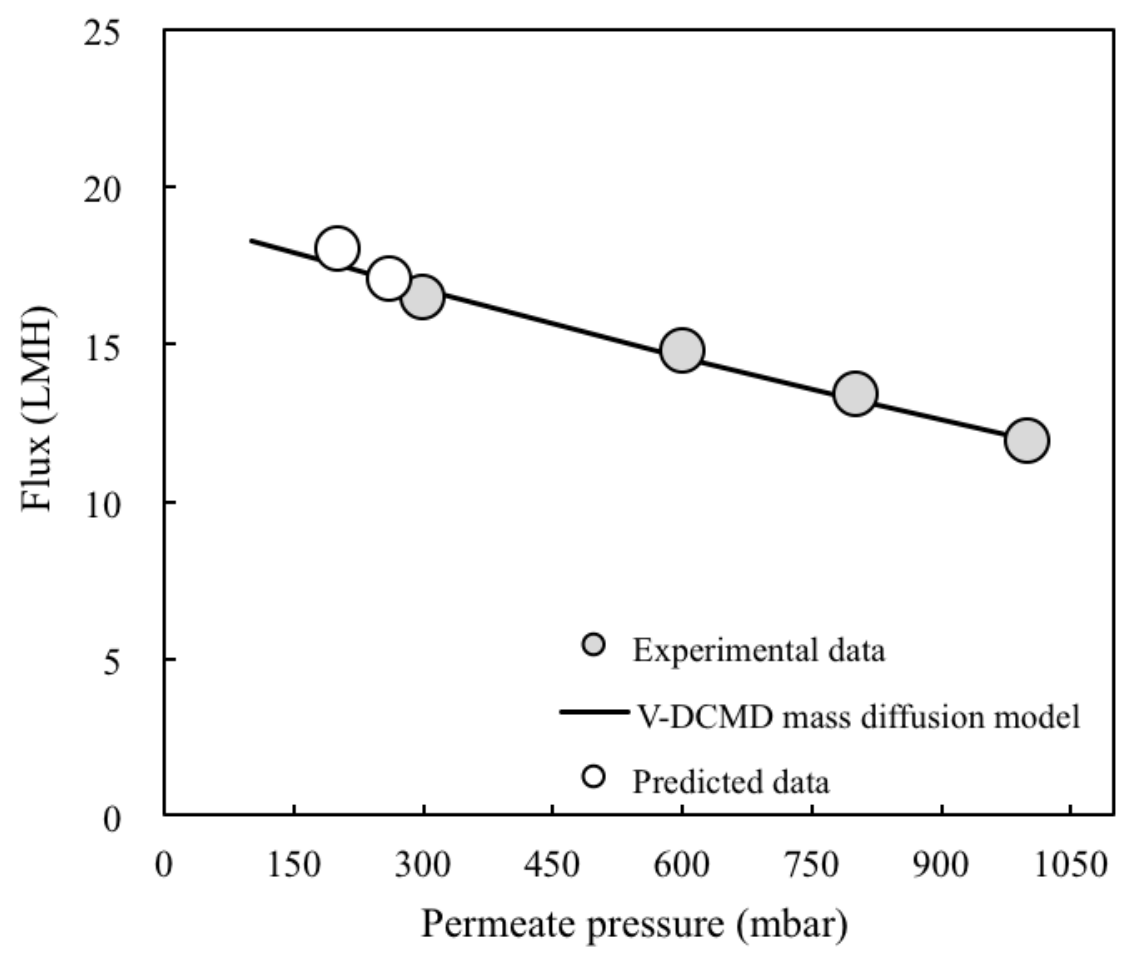

Fig. 5. V-DCMD experimental and modelling permeate flux as a function of vacuum pressure (feed water $=$ DI water, feed and permeate velocity $=0.06 \mathrm{~m} / \mathrm{s}$, feed temperature $=55^{\circ} \mathrm{C}$, and permeate temperature $\left.=25^{\circ} \mathrm{C}\right)$. 


\section{Feed}
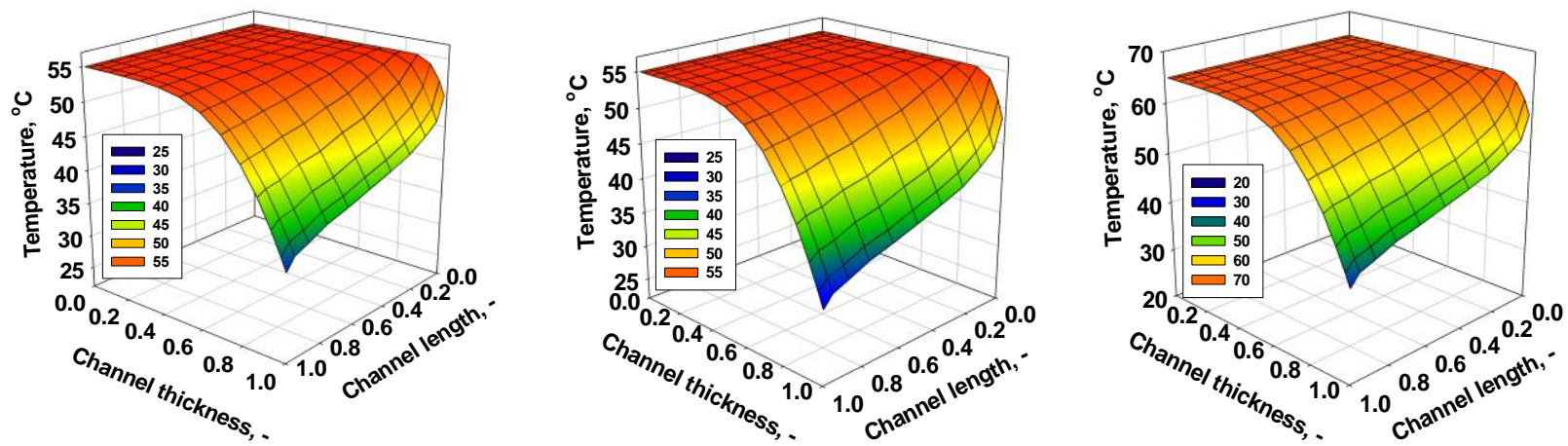

\section{Permeate}

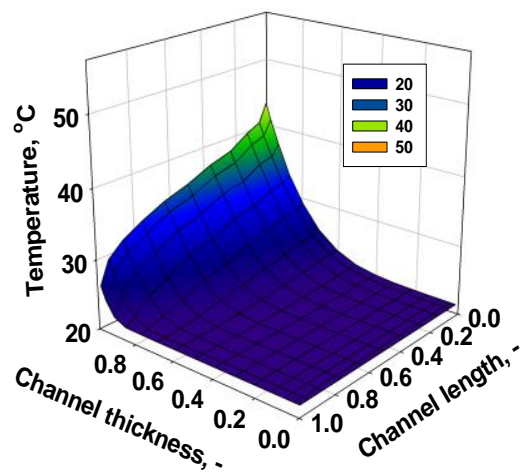

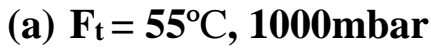

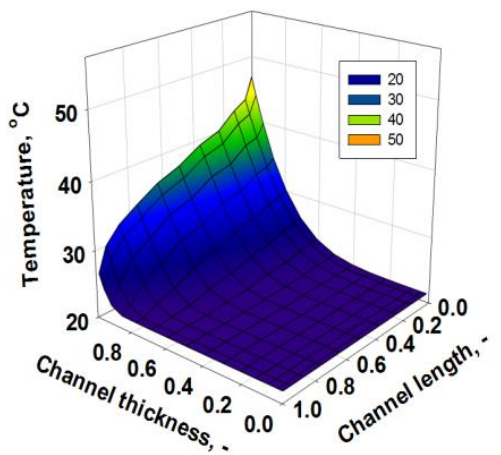

(b) $\mathbf{F}_{\mathbf{t}}=5^{\circ} \mathrm{C}, 300 \mathrm{mbar}$

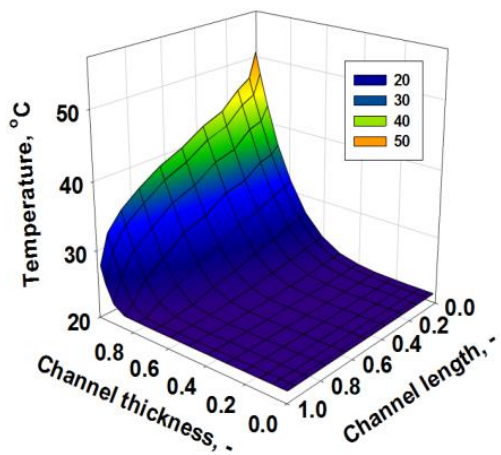

(c) $\mathrm{F}_{\mathrm{t}}=\mathbf{6 5}^{\circ} \mathrm{C}, 1000 \mathrm{mbar}$

Fig. 6. Temperature distribution profile along the membrane module channel length and thickness of feed and permeate side of V-DCMD (300 mbar) and DCMD (1000 mbar) at $\mathrm{F}_{\mathrm{t}}$ of $55^{\circ} \mathrm{C}$ and $65^{\circ} \mathrm{C}$. (channel thickness, from scale 0 to 1 ( 0 being furthest from the membrane, 1 being closest to the membrane; and channel length, from scale $0=$ inlet, $1=$ outlet). 

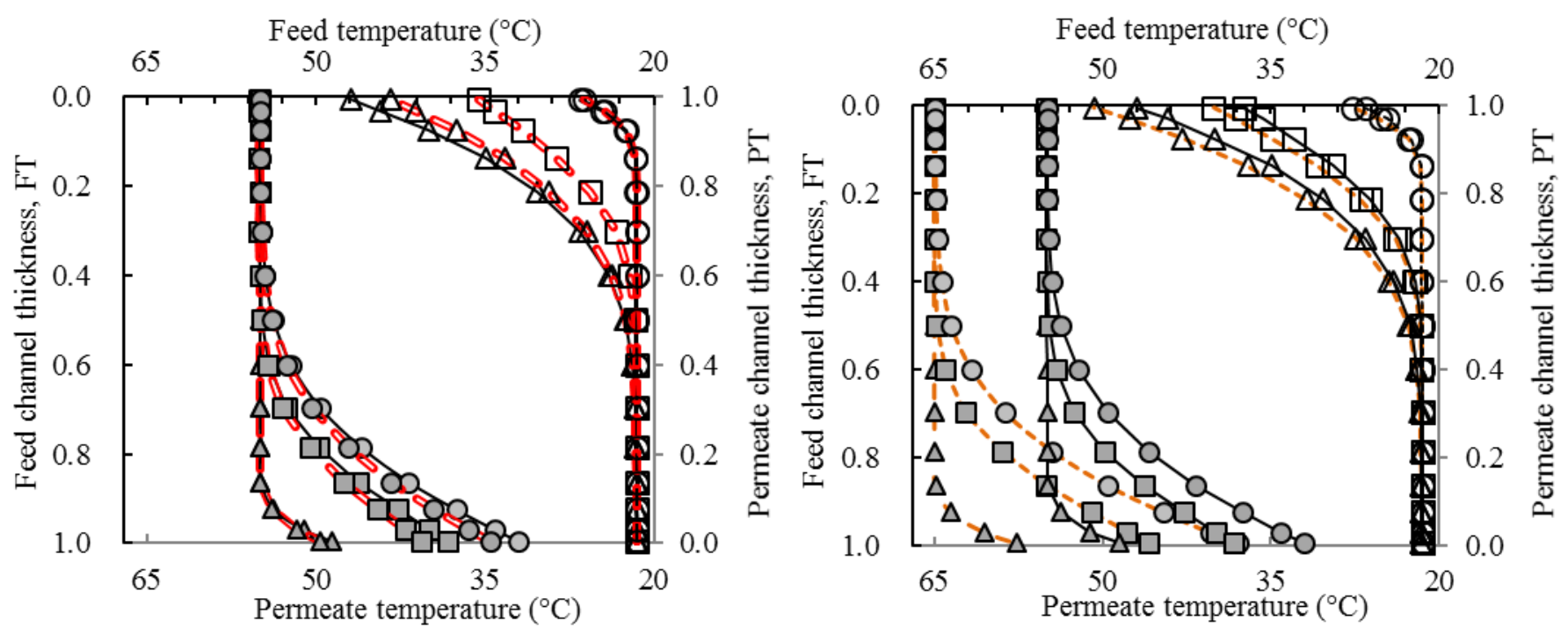

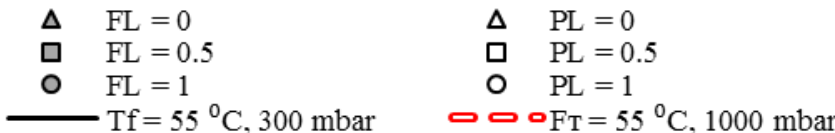

(a)

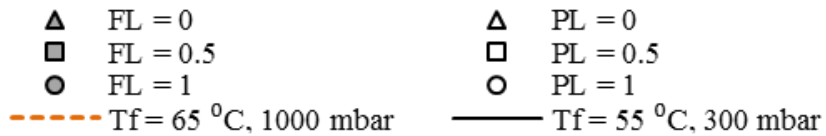

(b)

Fig. 7. Line scatter of temperature distribution profile along the feed and permeate side membrane channel length (FL and PL) and thickness (FT and PT) of (a) V-DCMD (300 mbar) and DCMD (1000 mbar) at $\mathrm{F}_{\mathrm{t}}$ of $55^{\circ} \mathrm{C}(\mathbf{b}) \mathrm{V}-\mathrm{DCMD}(300 \mathrm{mbar})$ and DCMD (1000 mbar) at $\mathrm{F}_{\mathrm{t}}$ of $55^{\circ} \mathrm{C}$ and $65^{\circ} \mathrm{C}$. (channel thickness, from scale 0 to 1 ( 0 being furthest from the membrane, 1 being closest to the membrane; and channel length, from scale $0=$ inlet, $1=$ outlet . 
(a)
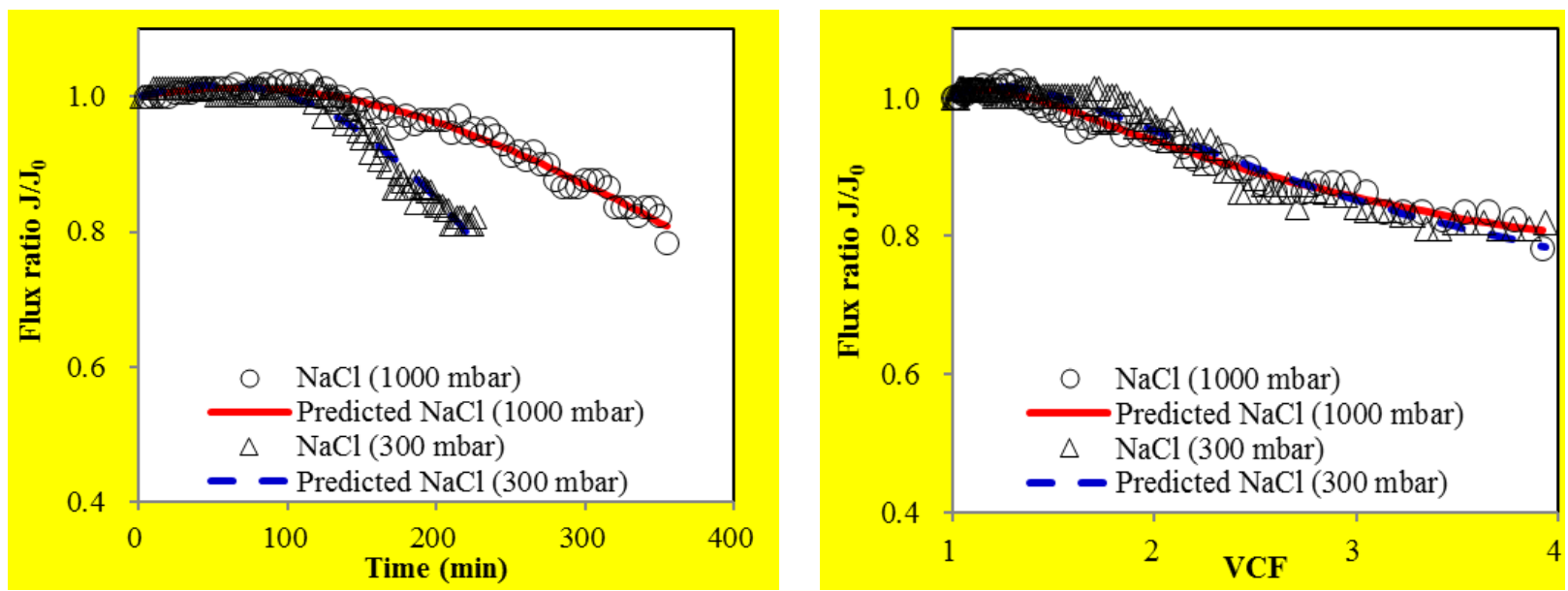

(b)
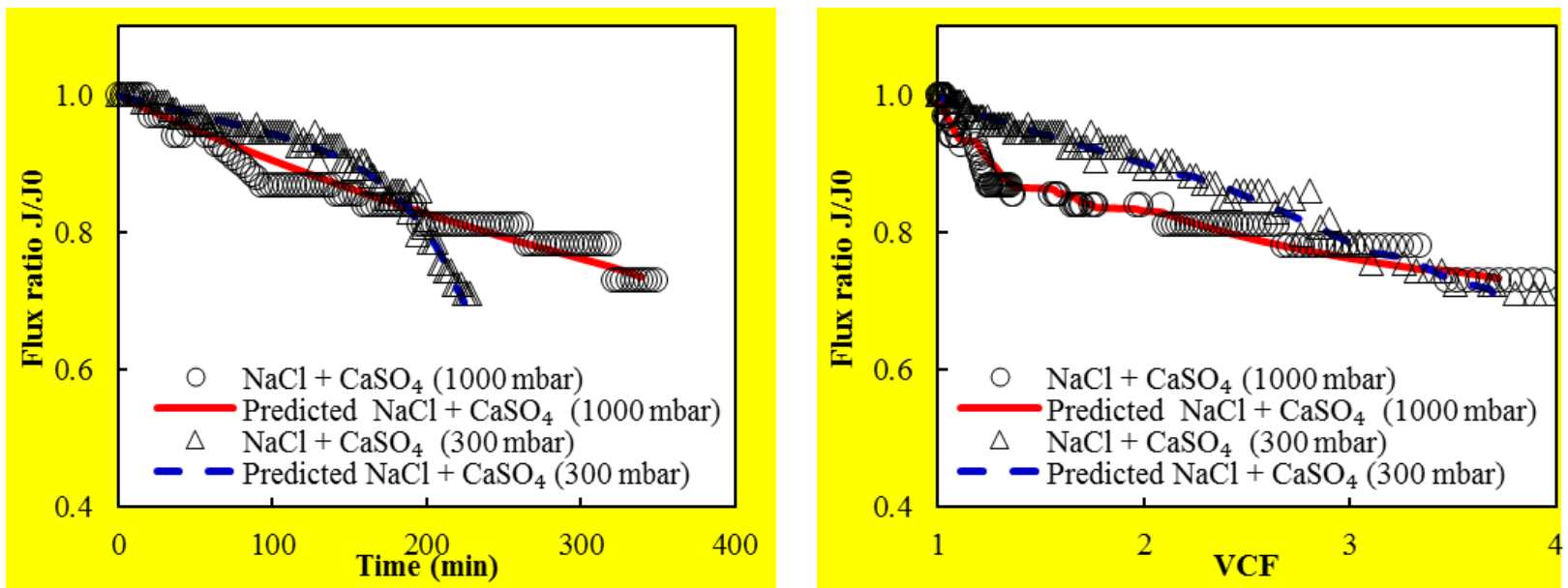

Fig. 8. Experimental and modelling data of the flux decline of DCMD (1000mbar, $\left.\mathrm{F}_{t}=55^{\circ} \mathrm{C}\right)$ and V-

DCMD (300mbar, $\left.\mathrm{F}_{\mathrm{t}}=55^{\circ} \mathrm{C}\right)$ as a function of time and VCF with feed solutions of (a) $\mathrm{NaCl}$, and (b) $\mathrm{NaCl}$ with $\mathrm{CaSO}_{4}$. 


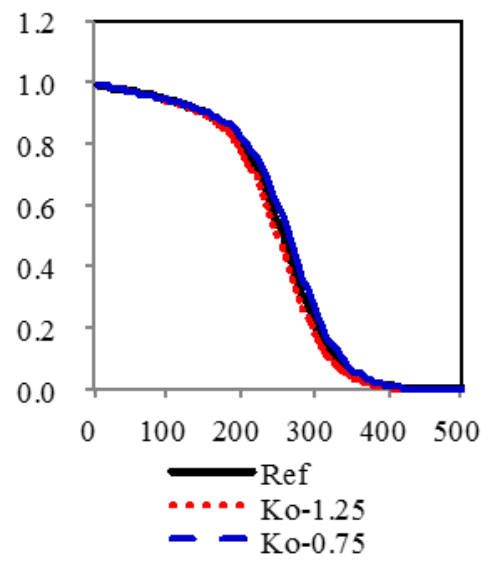

(a)

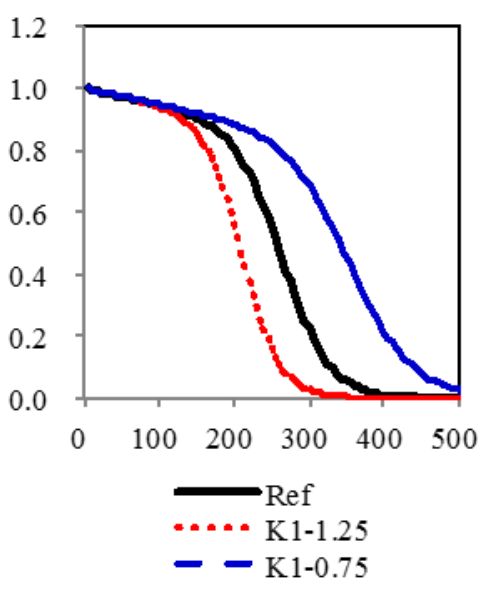

(b)

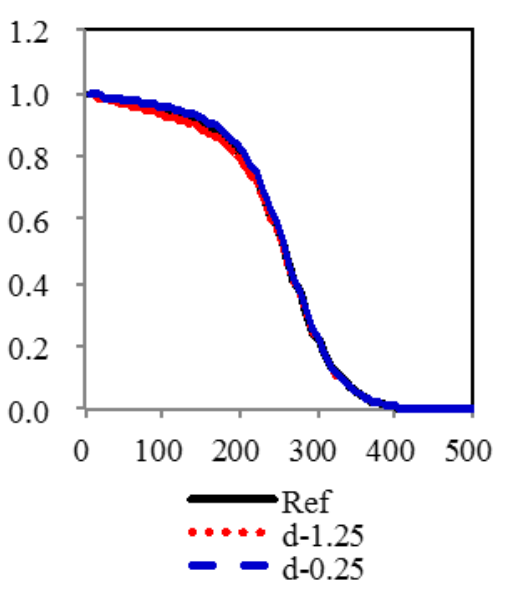

(c)

Fig. 9. Sensitivity test for coefficients of (a) $\mathrm{k}_{0}$, (b) $\mathrm{k}_{1}$, and (c) $\mathrm{d}$ (Ref $=1.0$ with increment and decrement of 25\%). 
(a)

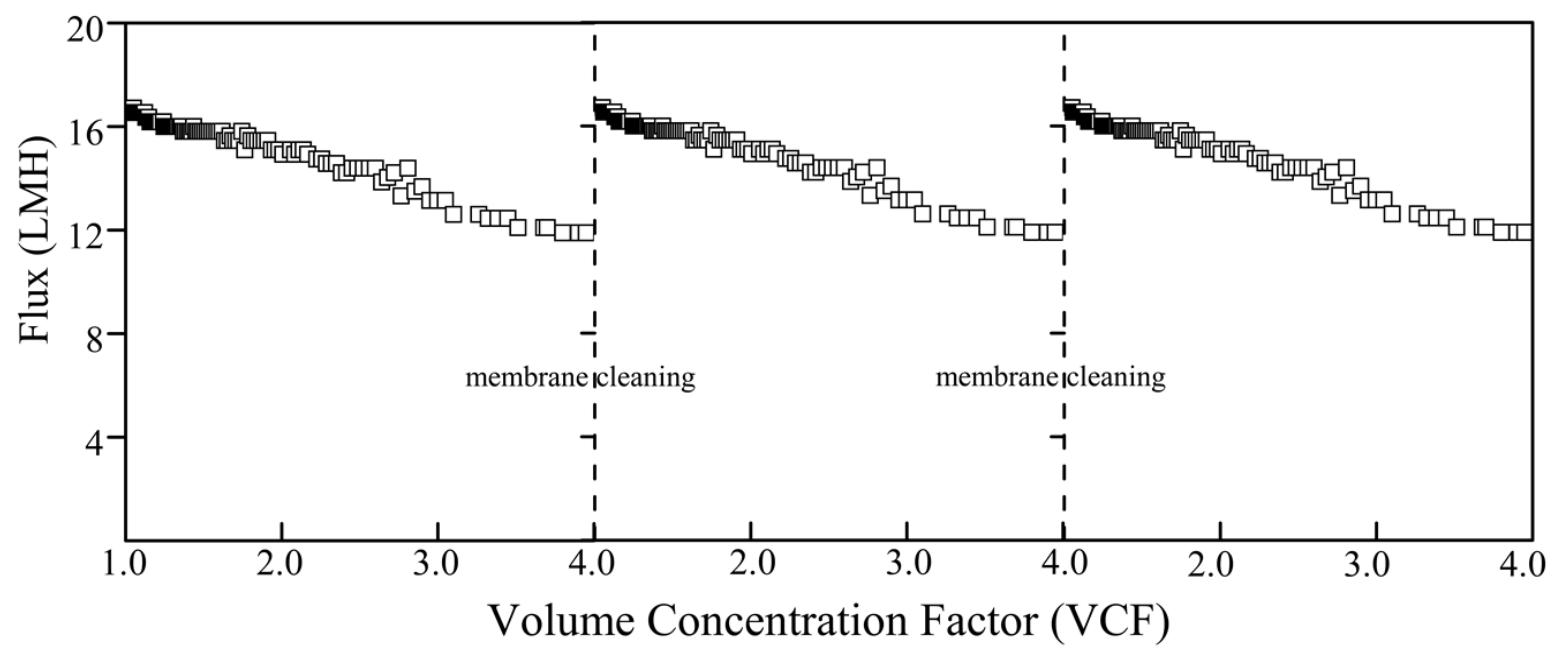

(b)
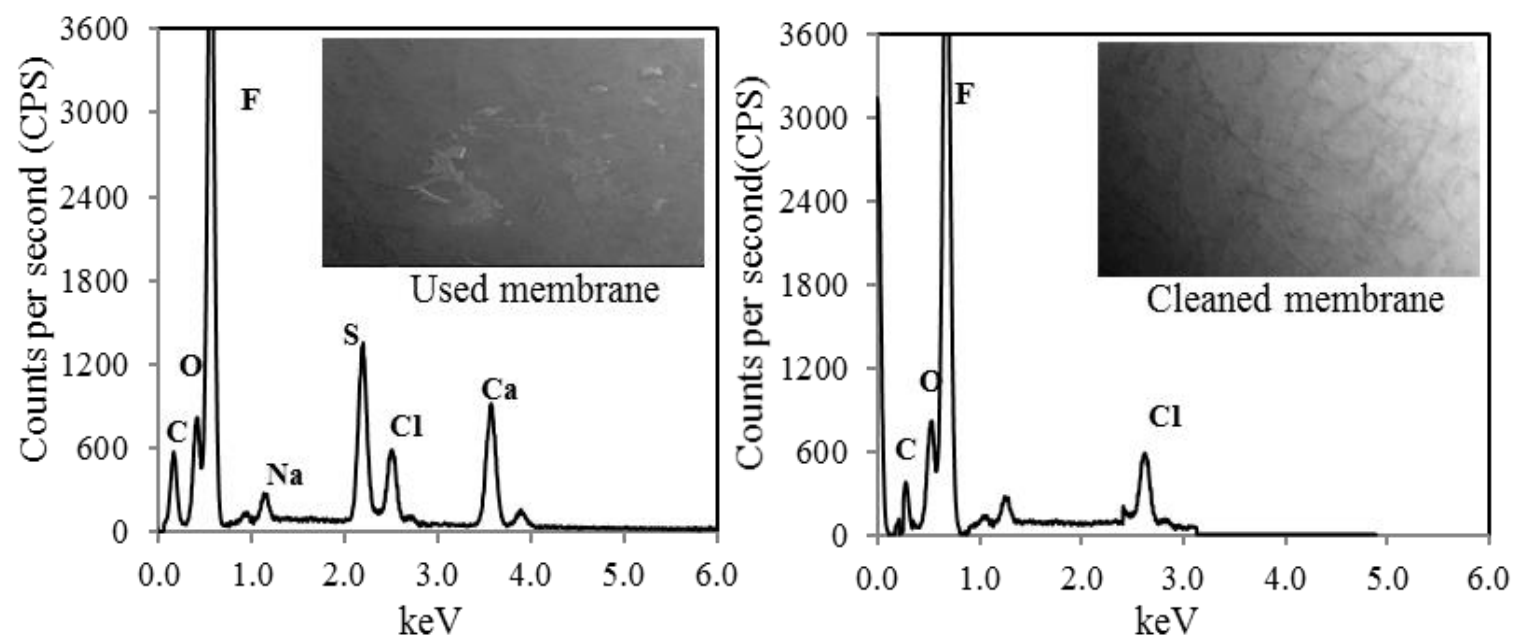

Fig. 10. Continuous operation of V-DCMD for ROC wastewater treatment: (a) permeate flux with intermittent membrane cleaning, and (b) SEM-EDX of used membrane and membrane after DI water flushing. 